\title{
Probabilistic ecotoxicological risk assessment of imidazolium ionic liquids with amino acid and halide anions
}

\section{Muhammad Ishaq Khan'1, Dzulkarnain Zaini ${ }^{1, ~}$, Azmi Mohd Shariff ${ }^{1}$ and Muhammad Moniruzzaman'}

${ }^{1}$ Centre of Advanced Process Safety (CAPS), Chemical Engineering Department, Universiti Teknologi Petronas, 32610 Bandar Seri Iskandar,

Perak Darul Ridzuan, Malaysia.

Phone: +605 - 368 7588; Fax: +6053656176

"Email: dzulkarnain.zaini@utp.edu.my

\begin{abstract}
Ionic liquids (ILs) are chemical substances with good solubility and low vapor pressure because they are ionized and therefore charged. ILs may damage ecosystem due to their good water solubility. Toxicological studies for individual ILs. Major constraint in ILs ecotoxicology is that risk cannot be quantified by risk quotient methods because of unavailability of exposure assessment data. At present, only limited information is available about the impacts of ILs to aquatic ecosystems. The main objective of the current work is to use statistical methods to available literature on acute toxicity data of ILs to assess potential ecotoxicological risks when the ILs do come into industrial use. Probabilistic ecotoxicological risk assessment (PETRA) method was adopted by using Chemical Toxicity Distributions (CTDs) and Species Sensitivity Distributions (SSDs). SSDs has been used to derive threshold values below which the ecosystem and its biotic components could be protected from the adverse effect of ILs. CTDs has been used to estimate the probability of finding ILs with an effect below a calculated concentration which is considered to be safe environmental concentration. Acute toxicity data were collected from the literature on the acute toxicity of four bacterial pathogens Aeromonas hydrophila, Escherichia coli, Listeria monocytogenes and Staphylococcus aureus. CTD method was applied to assess the distribution of toxicities of group of IL to individual species. The SSD method was applied to estimate guideline values $(\mathrm{GVs})$ to estimate different level of protection of bacterial species from ILs. Imidazolium chloride and bromide ILs were reported to pose more than $5 \%$ risk towards bacteria. Out of the four bacterial strains, $E$ coli was reported to be potentially at higher risk because of highest sensitivity when exposed towards ILs. The risk posed was five percent which is acceptable level of risk.
\end{abstract}

Keywords: Ionic liquids; Ecotoxicity; Species Sensitivity Distributions; Chemical Toxicity Distributions; Probabilistic Risk Assessment.

\section{INTRODUCTION}

ILs are chemical substances with the capabilities to replace the conventional organic solvents. They have good solubility and low vapor pressure because they are ionized and therefore charged [1]. Potential applications may range from separation processes, catalytic activity, and synthesis, as well as in the research area of emerging chemicals [2-8]. ILs do not contribute to air pollution as like the 
gases or other industrial chemicals because of lower vapor pressure, but they may harm the ecosystem due to good solubility [9-12]. ILs are toxic towards biotic components of ecosystems, including aquatic species[13]. Conventional toxicological research on ILs focused only on the toxicity assessment. There are a lot of species on individual ILs available in the literature [14]. Since ILs are not still used in industries, therefore there is a lack of industrial data. At present only limited information is available about the impacts of ILs on the environment[15], so it is difficult to get exposure data for ecotoxicological risk.

Conventionally, ecological risk assessment (ERA) methodologies are adopted to estimate the probability and the extent of the adverse effect of exposure to toxic chemicals towards ecosystems[16]. The ERA is characterized by effect and exposure assessment [17]. Effect assessment is carried out by performing acute toxicity testing and then NOEC or PNEC are estimated from the toxicity results by using appropriate assessment factors[18]. However, NOECs have been criticized for a variety of reasons [19]. As ILs are new class of chemicals having no major industrial data of leakage into aquatic ecosystems. Therefore, only the effect assessment is carried out either by experimental studies or by modeling techniques to predict toxicity of new ILs[20]. As individual species are not the representatives of cumulative aquatic population, therefore only the effect assessment is not enough to assess ecotoxicological risks of ILs. Another major issue in the assessment of ecotoxicological impacts of ILs on aquatic ecosystem is the limitation in chronic toxicity data. [21].

Traditionally, the toxicity was either evaluated by experimental the acute toxicity studies or predicted by various techniques amongst which QSAR is one of the best techniques[22]. However, it is impossible to test the impacts of all ILs on all species. Laboratory generated data of single species is considered for the hazard ranking only in the ecotoxicological assessment of ILs. Conventionally, the toxic effect of a single ILs is tested on individual organism representatives of various species of ecosystems. Although the results produced are usually accurate and a lot of information on the toxicity of ILs towards individual species are validated through a number of acute toxicity tests, it is desirable to assess the cumulative impacts of ILs to the environment, especially aquatic ecosystems. Even though there are no evidence of exposure of the aquatic organism to ILs in real life, but the use of analytical techniques to translate laboratory acute toxicity data can help to develop tools for the potential ecotoxicological risk assessment. The objective of current work is the extrapolation of the results from a relatively small set of acute toxicity data to assess the distribution of toxicities of ILs to a range of species and the sensitivities of these species towards imidazolium ILs by statistical methods.

In recent years, Species Sensitivity Distributions (SSDs) have become the preferred method of determining PNECs [23]. Different species may react to toxicants in differ way because of a number of reasons. Hence SSD provide a better assessment method to cover this gap [24]. However, no one of the SSD methods had been allied to imidazolium ILs. Furthermore, exposure assessment is carried out by monitoring some real exposure data (measure environmental concentrations, MEC) or from modeling approaches (Predicted Environmental Concentrations, PEC) [25]. The ERA could have been applied only if ILs have some real exposure data. Since ILs didn't have any major industrial applications so far, a method of risk assessment which would not require exposure data is adopted in the current research. Therefore, only available toxicity data are used to calculate CTDs and SSDs. CTDs method has been used in environmental risk assessment for assessment of pharmaceutical effects on aquatic plants but this methods had never been use $\mathrm{d}$ for ILs risk assessment [19, 26, 27]. To address the problem of unavailability of release data of ILs the probabilistic techniques may provide best solution. As, CTD gives the probability of finding a toxic chemical below a certain concentration of the tested organisms. Therefore, probabilistic risk assessment methodology incorporating CTD and SSD methods might be one of the best solutions for ecotoxicological risk assessment of imidazolium ILs. 


\section{MATERIALS AND METHODS}

\section{Selection of Ionic liquids}

ILs are emerging solvents and the family of ILs based on imidazolium has the potential for many industrial processes and applications[28]. A number of acute toxicity data are available for the imidazolium ILs. In all toxicological publications on ILs until 2015, 48 \% ILs are the Imidazolium ILs[29]. This show that amongst all ILs, Imidazolium ILs are important because of their potential industrial applications. This data may be used for the alternative methods to assess the ecotoxicological risk of ILs as traditional toxicological studies of ILs do not account for risk assessment. Therefore, imidazolium ILs with different alkyl chain and two types of anions (halide, and amino acids) were selected for to apply PETRA method.

\section{Data Selection}

As ILs are still new liquids with no industrial use, only laboratory toxicity data were available. The data for the current work were obtained from the published experimental studies on the toxicity of ILs performed by Ghanem et al. 2015 [30]. In their work, they used four species of pathogenic bacteria, Listeria monocytogenes, Staphylococcus aureus, Escherichia coli and Aeromonas hydrophila. Antimicrobial test were performed by them using standard micro-broth dilution test [31, 32]. Toxicity data obtained from their work are presented in Table1.

Table 1. Toxicity of Imidazolium ILs towards bacteria

\begin{tabular}{|c|c|c|c|c|}
\hline \multirow[t]{2}{*}{ Ionic Liquids } & \multicolumn{4}{|c|}{$\begin{array}{c}\text { EC50 } \\
(\mathrm{mmol} / \mathrm{L})[30]\end{array}$} \\
\hline & A hydrophila & E coli & L monocytogenes & $S$ aureus \\
\hline$[\mathrm{C} 4 \mathrm{mim}][\mathrm{Cl}]$ & 75.83 & 80.05 & 85.75 & 69.19 \\
\hline$[\mathrm{C} 2 \mathrm{OHmim}][\mathrm{Ser}]$ & 76.99 & 76.6 & 85.46 & 73.86 \\
\hline [C2OHmim][Pro] & 49.56 & 43.84 & 48.88 & 43.19 \\
\hline$[\mathrm{C} 4 \mathrm{mim}][\mathrm{Br}]$ & 47.17 & 43.21 & 42.5 & 42.85 \\
\hline [C2OHmim][Gly] & 34.92 & 34.72 & 33.71 & 33.69 \\
\hline [C2OHmim][Ala] & 25.64 & 23.86 & 26.37 & 22.47 \\
\hline [C6mim] $[\mathrm{Br}]$ & 12.73 & 11.23 & 11.25 & 9.91 \\
\hline$[\mathrm{C} 6 \mathrm{mim}][\mathrm{Cl}]$ & 8.53 & 11 & 13.05 & 11.81 \\
\hline$[\mathrm{C} 8 \mathrm{mim}][\mathrm{Ser}]$ & 4.72 & 4.74 & 4.68 & 5.03 \\
\hline [C8mim][Pro] & 4.07 & 3.33 & 3.72 & 4.09 \\
\hline [C8mim][Gly] & 2.82 & 2.72 & 2.72 & 2.49 \\
\hline [C8mim][Ala] & 2.75 & 2.73 & 2.62 & 2.72 \\
\hline [C8mim][Asn] & 2 & 2 & 2.05 & 2.07 \\
\hline$[\mathrm{C} 8 \mathrm{mim}][\mathrm{Cl}]$ & 1.48 & 1.66 & 1.63 & 1.41 \\
\hline$[\mathrm{C} 8 \mathrm{mim}][\mathrm{Br}]$ & 1.25 & 1.12 & 1.24 & 1.05 \\
\hline$[\mathrm{C} 10 \mathrm{mim}][\mathrm{Br}]$ & 0.1 & 0.1 & 0.11 & 0.1 \\
\hline$[\mathrm{C} 12 \mathrm{mim}][\mathrm{Br}]$ & 0.05 & 0.05 & 0.06 & 0.06 \\
\hline
\end{tabular}


The results obtained from their work were according to accepted trends in ILs toxicology. The effect of alky chain length, amino acid anions and functional group were good enough as they reflect common trends found in peer literature review [33, 34].

\section{Chemical Toxicity Distributions (CTDs) and Species Sensitivity Distributions (SSDs)}

\section{Chemical Toxicity Distributions}

Chemical toxicity distribution method is applied when a group of chemicals with the same mode of actions are used and there is a need of assessment of the group towards the environmental species $[19,35,36]$. In CTDs method, For each species, the EC50 data for all ILs (Table 1) were used to calculate CTDs according to the methods outlined by Williams et al 2011[27]. CTDs based on EC50 were used since there were no EC10 data available. The EC50 data for all compounds for a given species were ranked in Excel. The ranks were converted to \% ranks (j) using the Weibull formula [37] :

$$
J=\frac{100 \times i}{n+1}
$$

Where $j$ is percent rank $i$ is the rank and $n$ is the total number of compounds. The CTDs were graphed in Excel by plotting the probit of the \% rank, calculated as $=\operatorname{NORMINV}((\mathrm{j}), 5,1)$ where NORMINV returns the normal cumulative distribution function, against the EC50 of the compounds. A linear regression was then performed in Excel. The threshold values were calculated from the CTDs curves which provided the concentrations of the group of ILs towards individual species.

\section{Species Sensitivity Distributions}

Species sensitivity distribution is a statistical distribution method which describes the sensitivity of a toxicant towards a set of species[38]. As there are a large number of species in our ecosystem, therefore we may not know the true distribution of toxicity endpoints. Hence, SSD is used to estimate the sensitivity by using toxicity data of the individual chemicals towards a set of species and visualized as cumulative distribution function [39]. SSDs are presented in curves which are is basically cumulative distribution function of toxicity data performed at laboratory level using a single species. These curves derive Guideline values (GVs) to quantify ecotoxicological risk. Only limited research had been carried out using SSDs for ILs toxicity [40] but these results could not provide a way to assess ecotoxicological risks of ILs.

For each IL, the package BurrliOz 2 was used to derive an SSD using EC50 data for all four bacterial species. Because there were four species, the package fitted a log-logistic curve to the data [41]. BurrliOz produced a graph of the SSD and calculated the GVs to protect $80 \%, 90 \%$, $95 \%$, and 99\%. GVs were taken as toxicity threshold values for the assessment of ecotoxicological risks [42]. SSD analysis evaluated the effects of individual ILs on a range of selected organisms. GVs were used as Predicted Environmental Concentrations (PECs) which can be compared with PNECs to quantify risk by hazard quotient method[43]. 


\section{RESULTS AND DISCUSSION}

\section{Chemical Toxicity Distributions}

For the sake of proper data processing, we divided the data into three groups, namely type-I (imidazolium Chloride and Imidazolium Bromide ILs), type-II (Amino acids Imidazolium ILs with C2OH) and type-III ILs (Amino acids Imidazolium ILs with C8 alkyl chain). Williams et al 2011 have defined 1st and the 5\% values as their Screening Point Values (SPVs)[27]. To estimate the concentrations expected to have no effect, SPVs referring to 1st and 5th centiles were divided by an assessment factor of 1000 to obtain the Screening Predicted No Effect Concentration (SPNEC) [44, 45]. The CTD plots of imidazolium chloride and imidazolium bromide ILs for all four species were shown in Figure 1. Similarly, the CTD plots for amino acids Imidazolium ILs were shown in Figure 2 and Figure 3.
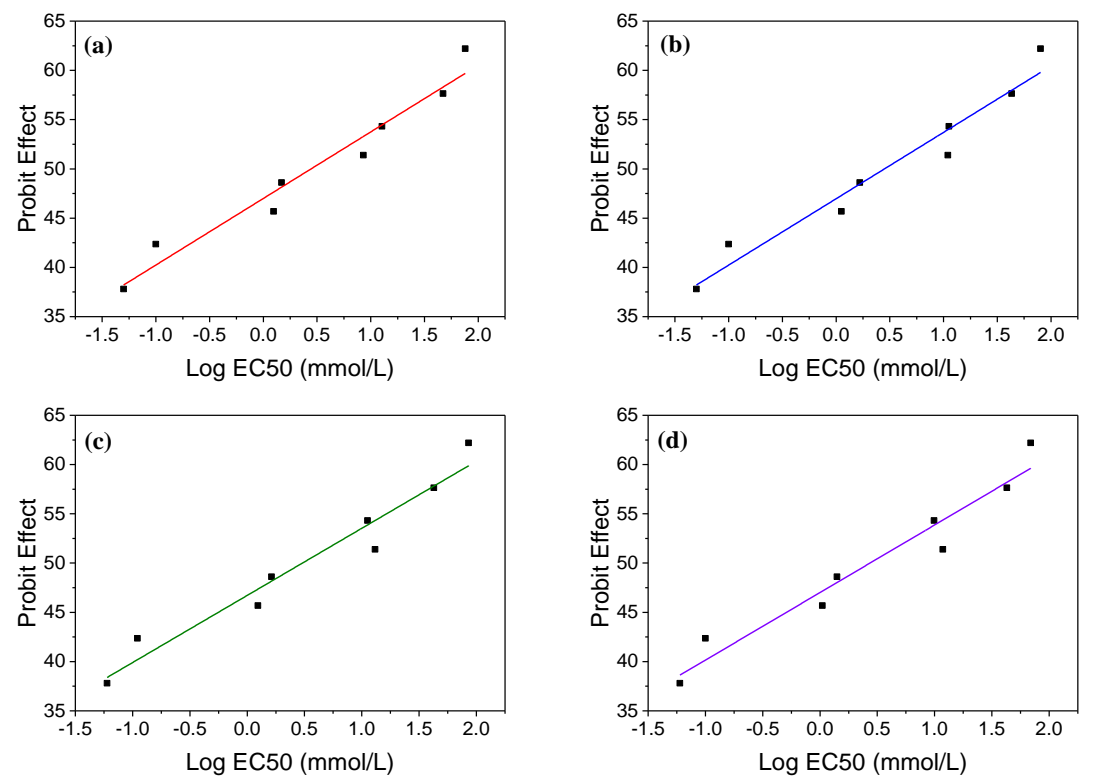

Figure 1. Probit effect of Type-I ILs towards A hydrophila (a), E coli (b), L monocytogenes (c), $S$ aureus $(\mathrm{d})$

SPVs were calculated based on CTD curves. SPENCs were calculated by dividing an assessment factor of 1000 to SPVs to compensate uncertainties in the toxicity data. The concentration against 5th percentile was considered to be a safe concentration [3] for the selected species. It is indicated that if the selected ILs were exposed to one of four bacteria A hydrophila, E coli, L monocytogenes and $S$ aureus, the SPNEC will be considered as safe concentration. Exceeding to SPNEC values will exceed risk to four bacteria of the inhabitant of that environmental compartment. The acceptable risk of the toxicants towards the selected species of an ecosystem by SSD is $5 \%$. If the exposure concentration is less than SPNEC, there will be risk to the species under studied. The SPNECs estimated from CTD analysis are tabulated in Table 2, 3 and 4. 

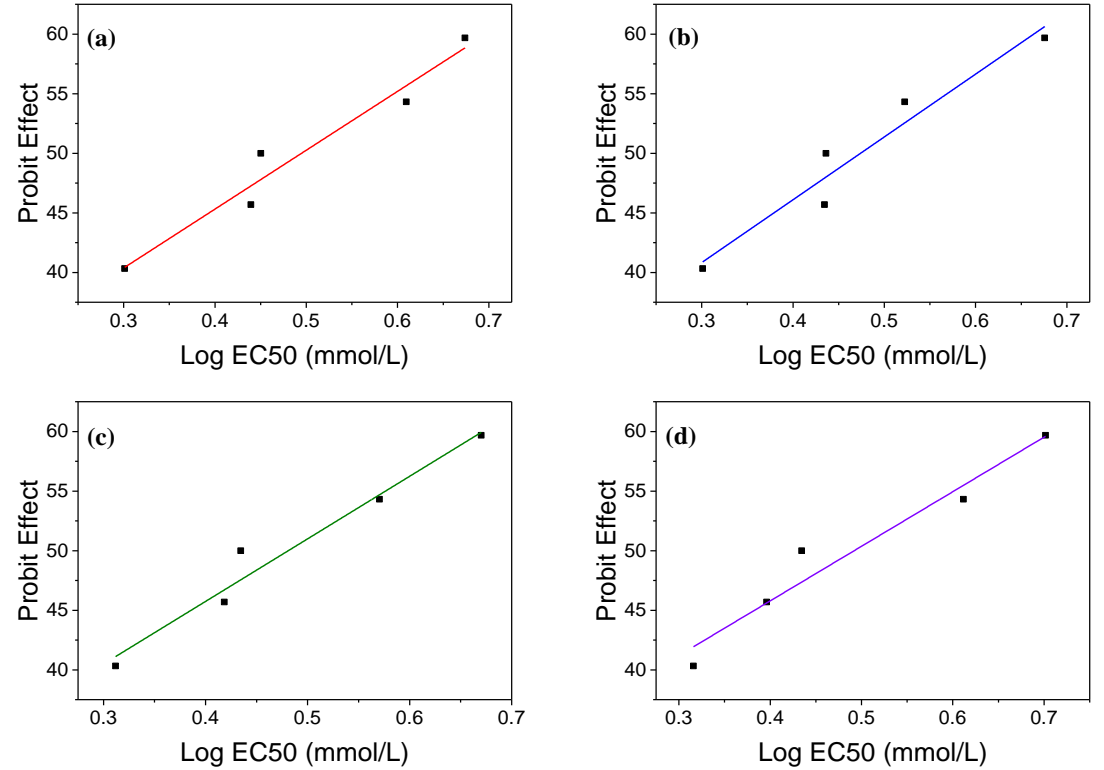

Figure 2. Probit effect of Type- II ILs towards A hydrophila (a), E coli (b), L monocytogenes (c), $S$ aureus (d)
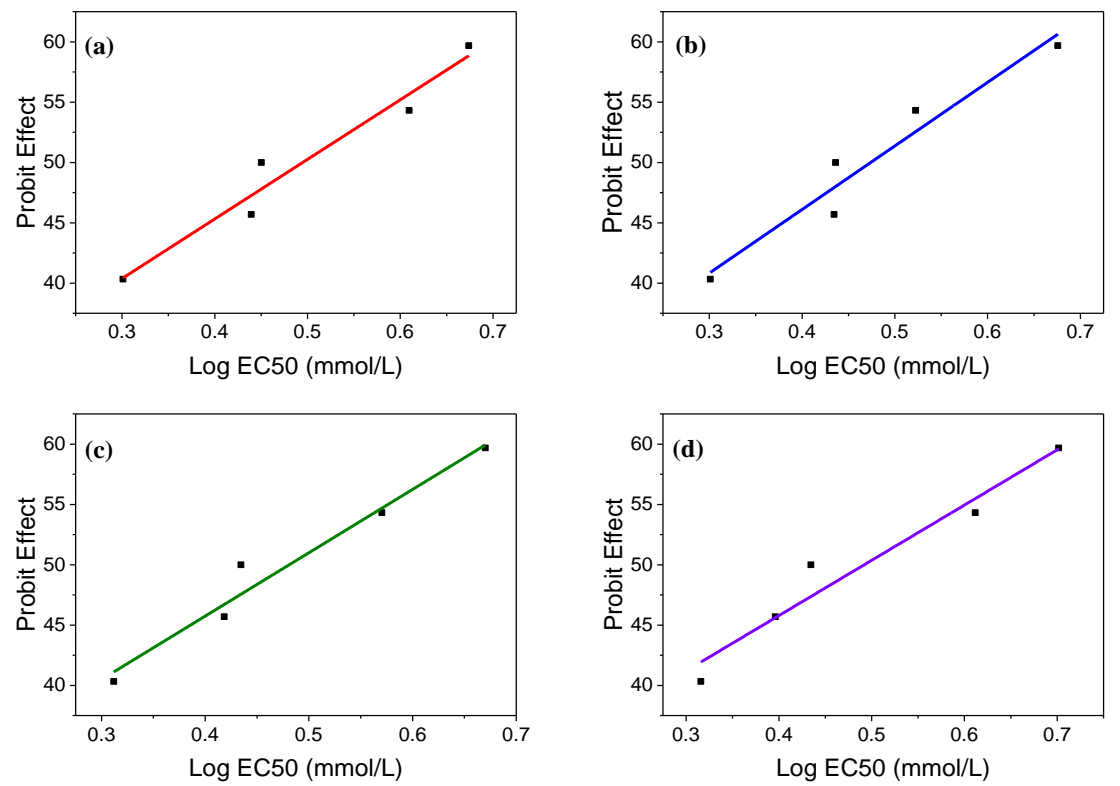

Figure 3. Probit effect of Type-III ILs towards A hydrophila (a), E coli (b), L monocytogenes (c), $S$ aureus (d) 
Table 2. Screening Predicted No-Effect Concentrations Based on Chemical Species Distributions screening: Type-1 ILs

\begin{tabular}{|c|c|c|c|c|}
\hline Organism & No. of ILs & Centile & $\begin{array}{c}\text { SPV } \\
(\mathrm{mmol} / \mathrm{L})\end{array}$ & $\begin{array}{c}\text { SPNEC } \\
(\mathrm{mmol} / \mathrm{L})\end{array}$ \\
\hline \multirow{2}{*}{ A hydrophila } & \multirow{8}{*}{8} & $1 \mathrm{st}$ & 0.0094169 & $94.2 \times 10-5$ \\
\hline & & 5 th & 0.0452276 & $4.52 \times 10-5$ \\
\hline \multirow{2}{*}{ E coli } & & $1 \mathrm{st}$ & 0.0009908 & $9.91 \times 10-5$ \\
\hline & & 5 th & 0.0101807 & $1.02 \times 10-5$ \\
\hline \multirow{2}{*}{ L monocytogenes } & & $1 \mathrm{st}$ & 0.0011937 & $119.37 \times 10-5$ \\
\hline & & 5 th & 0.0118663 & $1.19 \times 10-5$ \\
\hline \multirow{2}{*}{ S aureus } & & $1 \mathrm{st}$ & 0.0011371 & $11.4 \times 10-5$ \\
\hline & & 5 th & 0.0111187 & $1.11 \times 10-5$ \\
\hline
\end{tabular}

PNECs for the selected imidazolium ILs were observed to have 0.000009414 to $0.0004522 \mathrm{mmol} / \mathrm{L}$ of concentration for type-1 ILs safe environmental range for $A$ hydrophila at very low risk level ( $1^{\text {st }}$ centile) and acceptable risk level ( $5^{\text {th }}$ centile) consecutively.

Table 3. Screening Predicted No-Effect Concentrations based on Chemical Species Distributions screening: Type-II ILs

\begin{tabular}{|c|c|c|c|c|}
\hline Organism & No. of ILs & Centile & $\mathrm{SPV}(\mathrm{mmol} / \mathrm{L})$ & SPNEC $(\mathrm{mmol} / \mathrm{L})$ \\
\hline \multirow{2}{*}{ A hydrophila } & & $1 \mathrm{st}$ & 9.242303284 & $924.2 \times 10-5$ \\
\hline & & 5 th & 14.49952114 & $1449.9 \times 10-5$ \\
\hline \multirow[t]{2}{*}{ E coli } & 4 & $1 \mathrm{st}$ & 8.245450458 & $825.0 \times 10-5$ \\
\hline & & 5 th & 13.17572828 & $1317.5 \times 10-5$ \\
\hline \multirow{2}{*}{$L$ monocytogenes } & & $1 \mathrm{st}$ & 8.142992623 & $814.3 \times 10-5$ \\
\hline & & 5 th & 13.33889725 & $1333.8 \times 10-5$ \\
\hline \multirow{2}{*}{$S$ aureus } & & $1 \mathrm{st}$ & 7.76790771 & $776.80 \times 10-5$ \\
\hline & & 5 th & 12.50126708 & $1250.1 \times 10-5$ \\
\hline
\end{tabular}

From SSDs analysis it was revealed that the Type-II ILs have SPNEC from 924.2 x 10-5 to 1449.9 x 10-5 mmol/L for $A$ hydrophila at very low risk level to acceptable risk level.The results of SSD of Type-III ILs were presented in Table 4. Type-III ILs were observed to have SPNEC from $105.6 \mathrm{x}$ $10^{-5} \mathrm{mmol} / \mathrm{L}$ to $119.9 \times 10^{-5} \mathrm{mmol} / \mathrm{L}$ for $A$ hydrophila which indicated an acceptable risk $(5 \%)$ at $119.9 \times 10^{-5} \mathrm{mmol} / \mathrm{L}$.

SPNECs indicated that amongst three different groups of ILs with the same mode of action, Type-I ILs had a potential to pose high risk to the selected species as the PNEC of type-II ILs were three order of magnitude. Similarly, the PNEC type-III ILs was also greater than one order of magnitude. Furthermore, it was concluded that if an ecosystem containing A hydrophila, E coli, L monocytogenes and $S$ aureus will be exposed to three groups of imidazolium ILs studied in current work, Type-II and type-III ILs would be at comparatively less risk. The comparison is witnessed by the fact that amino acids ILs were less toxic [30]. The different concentrations of the group of ILs 
highlighted the important of sensitivities of the species. The sensitivity of the species in response to toxic effects of ILs was analysed by SSD method.

Table 4. Screening Predicted No-Effect Concentrations Based on Chemical Species Distributions screening: Type-III ILs

\begin{tabular}{lcccc}
\hline Organism & No. of ILs & Centile & SPV(mmol/L) & SPNEC (mmol/L) \\
\hline \multirow{2}{*}{ A hydrophila } & $1 \mathrm{st}$ & 1.056551327 & $105.6 \times 10-5$ \\
\multirow{3}{*}{ E coli } & 5 th & 1.199705734 & $119.9 \times 10-5$ \\
& $1 \mathrm{st}$ & 1916.514866 & $19165 \times 10-5$ \\
L monocytogenes & 5 & 5 th & 16509.82906 & $165098 \times 10-5$ \\
& & $1 \mathrm{st}$ & 1.091175626 & $109.10 \times 10-5$ \\
S aureus & 5 th & 1.47137974 & $147.10 \times 10-5$ \\
& $1 \mathrm{st}$ & 0.964015497 & $96.40 \times 10-5$ \\
& 5 th & 1.357931023 & $135.70 \times 10-5$ \\
\hline
\end{tabular}

\section{Species Sensitivity Distributions}

Burrlioz2.0 is one of the software used for SSD analysis [46]. Species sensitivities distributions were calculated using the Burrlioz2.0 package to obtain guideline values (GVs) for different levels of protection SSD plots from each group for all 4 bacteria were generated and shown in figures 4,5 and 6. The SSD data provided different guideline values for all four bacteria at different levels of protection for each of the ILs.

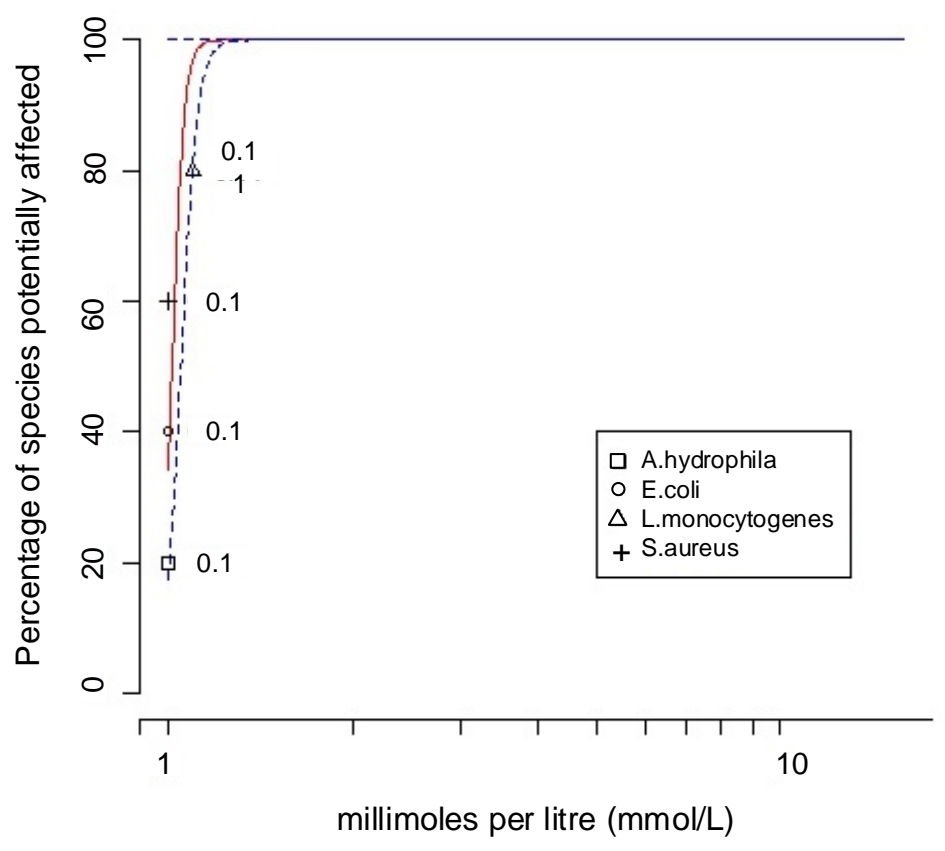

Figure 4. SSD curve for C10mimBr (type-1 ILS)

SSD for type-I ILs indicated that $\mathrm{C} 10 \mathrm{mimBr}$ had the worst effect on all four microbes. Estimated $5 \%$ of species will have an EC50 of less than $0.095 \mathrm{mmol} / \mathrm{L}(0.091-0.10 \mathrm{mmol} / \mathrm{L})$ or less at $95 \%$ protection level. 


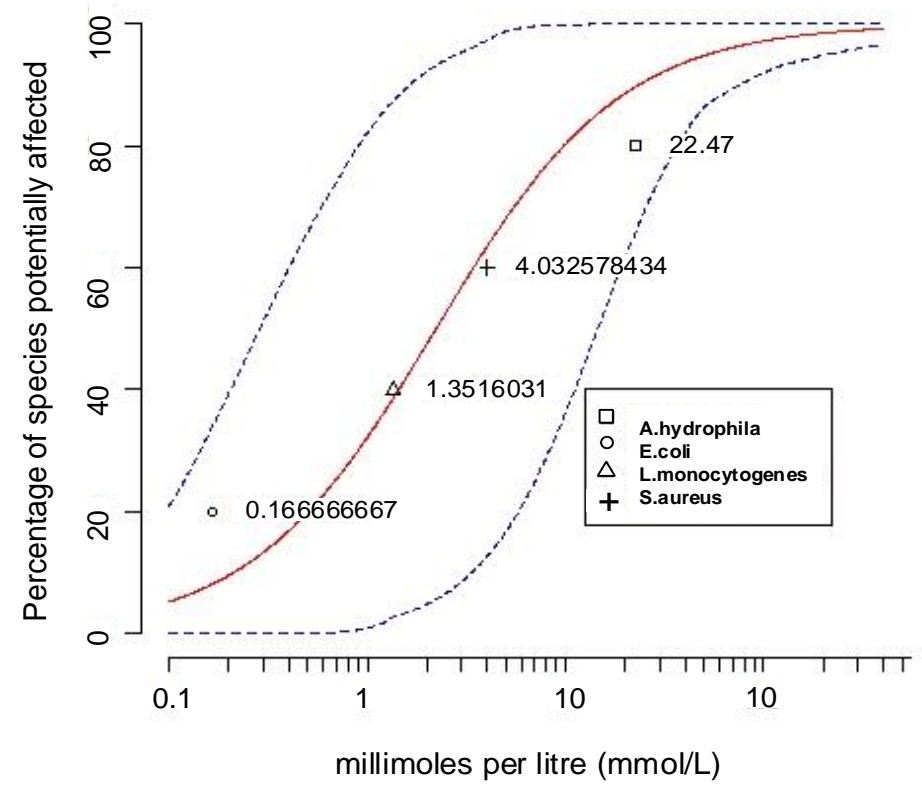

Figure 5. SSD curve for C2OHmimAla (type-II ILs)

SSD for type-II ILs indicated that C2OHmimAla had the worst effect on all four microbes. Estimated $5 \%$ of species will have an EC50 of less than $22 \mathrm{mmol} / \mathrm{L}(21-25 \mathrm{mmol} / \mathrm{L})$ or less at $95 \%$ protection level.

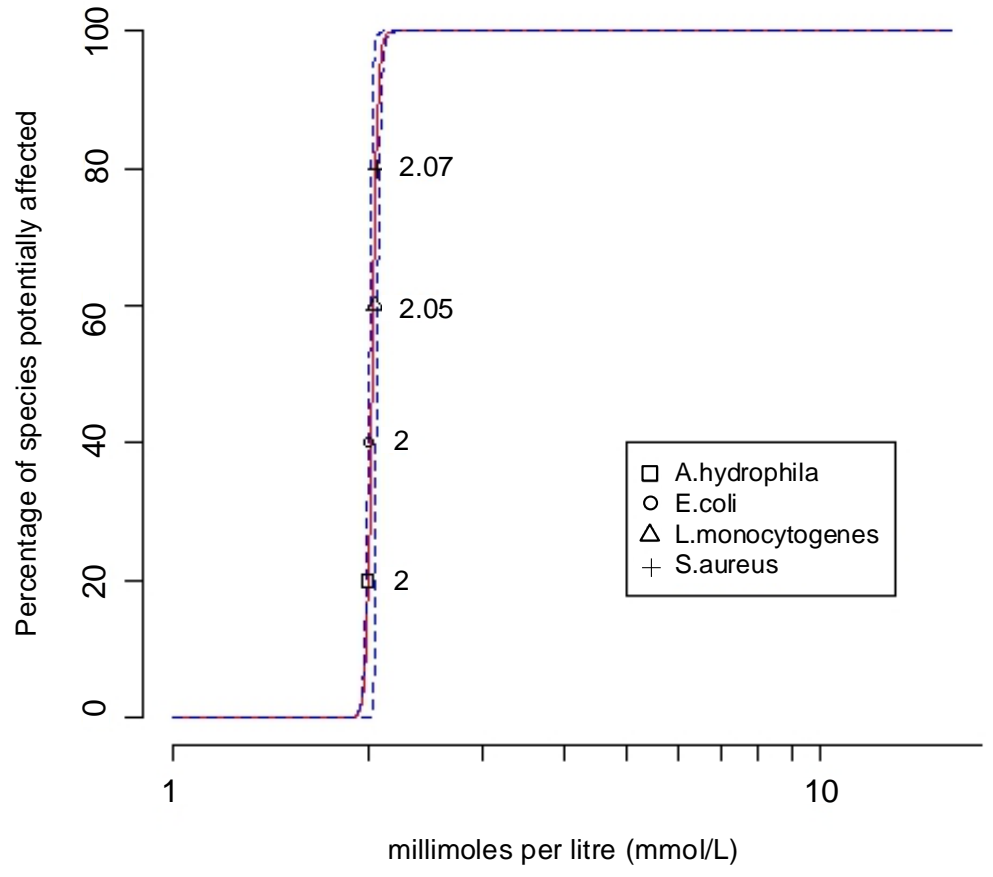

Figure 6. SSD curve for C8mimAs (type-III ILs)

SSD for type-III ILs indicated that C8mimAs had the worst effect on all four microbes. Estimated $5 \%$ of species will have an EC50 of less than $2 \mathrm{mmol} / \mathrm{L}$ (CI $2-2 \mathrm{mmol} / \mathrm{L}$ ) or less at $95 \%$ protection level. 
SSD analysis performed for three groups of ILs provided an understanding of how we can prioritize the use of chemicals into a specific environment. Especially aquatic compartment of ecosystem which are represented by four bacterial strains studied in current research. For example, amongst the studied ILs, C10MIMBr ILs having GV of $0.095 \mathrm{mmol} / \mathrm{L}$ were proved to be riskier as compared to C8MIMAs with $\mathrm{GV}$ of $2 \mathrm{mmol} / \mathrm{L}$ and $\mathrm{C} 2 \mathrm{OHMIMCl}$ with $22 \mathrm{mmol} / \mathrm{L}$ as $\mathrm{GV}$. The major reason for the higher sensitivity of selected bacteria towards ILs is the fact that amino acids IL were less toxic as compared to bromide or chloride ILs. Similarly, the higher sensitivity of imidazolium chloride is because of the combination of cation and anion in such a way that this cationic anionic interaction proved to be more toxic amongst other ILs of the same and other type of families.

\section{CONCLUSIONS}

The PETRA methodology presented an idea to assess the effect of individual ILs to a range of an organism or species along with the assessment of effects of a group of ILs to a single organism or species. Although not enough quality data was utilized in applying PETRA, this methodology still provided an idea for probabilistic measures for ecotoxicological assessment of ILs. SPNECs from CTDs indicated that amongst three sets of ILs with the same mode of action Type-I ILs are potentially risky toward the selected species.

Type-II and type-III ILs were noted to be at comparatively potentially less risky towards species under investigations in current research. This is because of amino acids ILs are considered to have low toxicity effect, hence low risk to the species Similarly the SSDs provided Guideline values for all three groups towards four species. Type-1 ILs having $0.095 \mathrm{mmol} / \mathrm{L}$ as Guideline Value was declared most risky toward selected species as compared to type-II ( $\mathrm{GV} 22 \mathrm{mmol} / \mathrm{L})$ and type-III ILs (GV $2 \mathrm{mmol} / \mathrm{L})$.

Amino Acids ILs are considered to have low toxicity because of which in current research Amino acids ILs (type-II and type-III) were proved to be less risky for selected species. ILs are replacing many industrial chemicals, therefore the methods applied for the ecotoxicological risk assessment on ILs in current work will directly affect industrial chemicals. As a result, environmental safety can be improved which will increase the importance of the use of probabilistic methodologies for newly synthesized industrial chemicals.

The major contribution of the current work is the assessment of ecotoxicological risk estimation even without the availability of exposure assessment data. In current work we have used EC50 values to calculate CTDs and SSDs, however more sensitive concentrations like EC20 could provide better risk assessment. Furthermore, the success of this methodology will enable risk assessors to integrate exposure end effect assessment methods to quantify ecotoxicological risk associated with the applications of ILs.

\section{ACKNOWLEDGEMENTS}

The author would like to acknowledge Universiti Teknologi PETRONAS, Centre of Advanced Process Safety (CAPS) and YUTP for providing the technical and financial assistance to this work. 


\section{REFERENCES}

[1] Feldmann C and Ruck M. Ionic Liquids-Designer Solvents for the Synthesis of New Compounds and Functional Materials. Zeitschrift für anorganische und allgemeine Chemie. 2017;643:2-2.

[2] Azam MA, Isomura K, Fujiwara A, and Shimoda T. Direct growth of vertically aligned single-walled carbon nanotubes on conducting substrate and its electrochemical performance in ionic liquids. physica status solidi (a). 2012;209:2260-2266.

[3] Cota I and Martinez FF. Recent advances in the synthesis and applications of metal organic frameworks doped with ionic liquids for $\mathrm{CO} 2$ adsorption. Coordination Chemistry Reviews. 2017.

[4] Mai NL and Koo YM. Enzymatic Reactions in Ionic Liquids. Emerging Areas in Bioengineering. 2018;1:35-65.

[5] Sahid N, Rahman M, Kadirgama K, and Maleque M. Experimental investigation on properties of hybrid nanofluids ( $\mathrm{TiO} 2$ and $\mathrm{ZnO}$ ) in water-ethylene glycol mixture. Journal Of Mechanical Engineering And Sciences. 2017;11:3087-3094.

[6] Sharma S, Tiwari A, Tiwari S, and Prakash R. Viscosity of hybrid nanofluids: Measurement and comparison. Journal Of Mechanical Engineering And Sciences. 2018;12:3614-3623.

[7] Ventura SP, e Silva FA, Quental MV, Mondal D, Freire MG, and Coutinho JA. Ionic-liquidmediated extraction and separation processes for bioactive compounds: past, present, and future trends. Chemical reviews. 2017;117:6984-7052.

[8] Yusoff N and Idris N. Ionic liquid based PVDF/PMMA gel polymer electrolyte for lithium rechargeable battery. Journal Of Mechanical Engineering And Sciences. 2017;11:31523165 .

[9] Thuy Pham TP, Cho C-W, and Yun Y-S. Environmental fate and toxicity of ionic liquids: A review. Water research. 2010;44:352-372.

[10] Latała A, Stepnowski P, Nędzi M, and Mrozik W. Marine toxicity assessment of imidazolium ionic liquids: acute effects on the Baltic algae Oocystis submarina and Cyclotella meneghiniana. Aquatic toxicology. 2005;73:91-98.

[11] Yan F, Shang Q, Xia S, Wang Q, and Ma P. Topological study on the toxicity of ionic liquids on Vibrio fischeri by the quantitative structure-activity relationship method. Journal of hazardous materials. 2015;286:410-415.

[12] Ding S, Chew T, Oh P, Ahmad A, and Jawad Z. Preparation of mixed matrix membrane using cellulose acetate incorporated with synthesized KIT-6 silica. Journal Of Mechanical Engineering And Sciences. 2018;12:3505-3514.

[13] Jastorff B, Störmann R, Ranke J, Mölter K, Stock F, Oberheitmann B, Hoffmann W, Hoffmann J, Nüchter M, and Ondruschka B. How hazardous are ionic liquids? Structureactivity relationships and biological testing as important elements for sustainability evaluation. Green Chemistry. 2003;5:136-142.

[14] Petkovic M, Seddon KR, Rebelo LPN, and Pereira CS. Ionic liquids: a pathway to environmental acceptability. Chemical Society Reviews. 2011;40:1383-1403.

[15] Matzke M, Stolte S, Thiele K, Juffernholz T, Arning J, Ranke J, Welz-Biermann U, and Jastorff B. The influence of anion species on the toxicity of 1-alkyl-3-methylimidazolium ionic liquids observed in an (eco)toxicological test battery. Green Chemistry. 2007;9:11981207.

[16] Manuilova A and Svensson H. Methods and tools for Assessment of Environmental Risk. Akzo Nobel Surface Chemistry, DANTES project. 2003. 
[17] Pastorok RA, Bartell SM, Ferson S, and Ginzburg LR. Ecological modeling in risk assessment: chemical effects on populations, ecosystems, and landscapes. CRC Press. 2016.

[18] Khan MI, Zaini D, Shariff AM, and Moniruzzaman M. Framework for Ecotoxicological Risk Assessment of Ionic Liquids. Procedia Engineering. 2016;148:1141-1148.

[19] Hanson ML and Solomon KR. New technique for estimating thresholds of toxicity in ecological risk assessment. Environmental science \& technology. 2002;36:3257-3264.

[20] Zhao Y, Zhao J, Huang Y, Zhou Q, Zhang X, and Zhang S. Toxicity of ionic liquids: database and prediction via quantitative structure-activity relationship method. Journal of hazardous materials. 2014;278:320-329.

[21] Ventura SP, Gonçalves AM, Sintra T, Pereira JL, Gonçalves F, and Coutinho JA. Designing ionic liquids: the chemical structure role in the toxicity. Ecotoxicology. 2013;22:1-12.

[22] Roy K, Das RN, and Popelier PL. Predictive QSAR modelling of algal toxicity of ionic liquids and its interspecies correlation with Daphnia toxicity. Environmental Science and Pollution Research. 2015;22:6634-6641.

[23] Santos J, Gonçalves A, Pereira J, Figueiredo B, e Silva F, Coutinho J, Ventura S, and Goncalves F. Environmental safety of cholinium-based ionic liquids: assessing structureecotoxicity relationships. Green Chemistry. 2015;17:4657-4668.

[24] Sanni S, Lyng E, Pampanin DM, and Smit MG. II. Species sensitivity distributions based on biomarkers and whole organism responses for integrated impact and risk assessment criteria. Marine environmental research. 2017;127:11-23.

[25] Pretti C, Renzi M, Focardi SE, Giovani A, Monni G, Melai B, Rajamani S, and Chiappe C. Acute toxicity and biodegradability of N-alkyl-N-methylmorpholinium and $\mathrm{N}$-alkylDABCO based ionic liquids. Ecotoxicology and Environmental Safety. 2011;74:748-753.

[26] Ab Rani M, Brandt A, Crowhurst L, Dolan A, Hassan NH, Hallett J, Hunt P, Lui M, Niedermeyer H, and Perez-Arlandis J. Erratum: Understanding the polarity of ionic liquids (Physical Chemistry Chemical Physics (2011) DOI: 10.1039/c1cp21262a). Physical Chemistry Chemical Physics. 2011;13:21653.

[27] Williams ES, Berninger JP, and Brooks BW. Application of chemical toxicity distributions to ecotoxicology data requirements under REACH. Environmental Toxicology and Chemistry. 2011;30:1943-1954.

[28] Yang J, Fan C, Kong D, Tang G, Zhang W, Dong H, Liang Y, Wang D, and Cao Y. Synthesis and application of imidazolium-based ionic liquids as extraction solvent for pretreatment of triazole fungicides in water samples. Analytical and bioanalytical chemistry. 20181-10.

[29] Heckenbach ME, Romero FN, Green MD, and Halden RU. Meta-analysis of ionic liquid literature and toxicology. Chemosphere. 2016;150:266-274.

[30] Ghanem OB, Mutalib MA, El-Harbawi M, Gonfa G, Kait CF, Alitheen NBM, and Leveque J-M. Effect of imidazolium-based ionic liquids on bacterial growth inhibition investigated via experimental and QSAR modelling studies. Journal of hazardous materials. 2015;297:198-206.

[31] Sosnowska A, Barycki M, Zaborowska M, Rybinska A, and Puzyn T. Towards designing environmentally safe ionic liquids: the influence of the cation structure. Green Chemistry. 2014;16:4749-4757.

[32] Latała A, Nędzi M, and Stepnowski P. Toxicity of imidazolium and pyridinium based ionic liquids towards algae. Chlorella vulgaris, Oocystis submarina (green algae) and Cyclotella meneghiniana, Skeletonema marinoi (diatoms). Green Chemistry. 2009;11:580-588.

[33] Hou X-D, Liu Q-P, Smith TJ, Li N, and Zong M-H. Evaluation of toxicity and biodegradability of cholinium amino acids ionic liquids. PloS one. 2013;8:e59145. 
[34] Bubalo MC, Hanousek K, Radošević K, Srček VG, Jakovljević T, and Redovniković IR. Imidiazolium based ionic liquids: effects of different anions and alkyl chains lengths on the barley seedlings. Ecotoxicology and Environmental Safety. 2014;101:116-123.

[35] Dobbins LL, Brain RA, and Brooks BW. Comparison of the sensitivities of common in vitro and in vivo assays of estrogenic activity: application of chemical toxicity distributions. Environmental toxicology and chemistry. 2008;27:2608-2616.

[36] Brain RA, Sanderson H, Sibley PK, and Solomon KR. Probabilistic ecological hazard assessment: Evaluating pharmaceutical effects on aquatic higher plants as an example. Ecotoxicology and Environmental Safety. 2006;64:128-135.

[37] Dobbins LL, Usenko S, Brain RA, and Brooks BW. Probabilistic ecological hazard assessment of parabens using Daphnia magna and Pimephales promelas. Environmental Toxicology and Chemistry. 2009;28:2744-2753.

[38] Church BG, Van Sprang PA, Chowdhury MJ, and DeForest DK. Updated species sensitivity distribution evaluations for acute and chronic lead toxicity to saltwater aquatic life. Environmental Toxicology and Chemistry. 2017.

[39] Leung KM, Bjørgesæter A, Gray JS, Li W, Lui GC, Wang Y, and Lam PK. Deriving sediment quality guidelines from field-based species sensitivity distributions. Environmental science \& technology. 2005;39:5148-5156.

[40] Santos JI, Goncalves AMM, Pereira J, Figueiredo B, e Silva F, Coutinho JAP, Ventura SPM, and Goncalves F. Environmental safety of cholinium-based ionic liquids: assessing structure-ecotoxicity relationships. Green Chemistry. 2015.

[41] MStJ W, Batley G, van Dam R, Chapman J, Fox D, Hickey C, and Stauber J. Revised Method for Deriving Australian and New Zealand Water Quality Guideline Values for Toxicants. Prepared for the Council of Australian Government's Standing Council on Environment and Water (SCEW). Department of Science. Information Technology and Innovation, Brisbane, Queensland. 2015.

[42] Warne MSJ. Derivation of the Australian and New Zealand water quality guidelines for toxicants. Australasian Journal of Ecotoxicology. 2002;7:123-136.

[43] Peterson RK. Comparing ecological risks of pesticides: the utility of a risk quotient ranking approach across refinements of exposure. Pest management science. 2006;62:46-56.

[44] Ng CKY, Lam JCW, Zhang XH, Gu HX, Li TH, Ye MB, Xia ZR, Zhang FY, Duan JX, and Wang WX. Levels of trace elements, methylmercury and polybrominated diphenyl ethers in foraging green turtles in the South China region and their conservation implications. Environmental Pollution. 2018;234:735-742.

[45] Wasserscheid P and Welton T. Ionic liquids in synthesis. John Wiley \& Sons. 2008.

[46] Binet MT, Adams MS, Gissi F, Golding LA, Schlekat CE, Garman ER, Merrington G, and Stauber JL. Toxicity of nickel to tropical freshwater and sediment biota: A critical literature review and gap analysis. Environmental Toxicology and Chemistry. 2017. 